\title{
Bi-aryl Analogues of Salicylic Acids: Design, Synthesis and SAR Study to Ameliorate Endoplasmic Reticulum Stress
}

\author{
Ye Eun Kim ${ }^{1} *$ \\ Dong Hwan Kim ${ }^{1, *}$ \\ Ami Choi ${ }^{l, *}$ \\ Seoul Jang' \\ Kwiwan Jeong (1D ${ }^{2}$ \\ Young-mi Kim' \\ Tae-gyu Nam (D) \\ 'Department of Pharmacy and Institute \\ of Pharmaceutical Science and \\ Technology, Hanyang University, Ansan, \\ Gyeonggi-do, I5588, Republic of Korea; \\ ${ }^{2}$ Gyeonggi Bio-Center, Gyeonggido \\ Business \& Science Accelerater, Suwon, \\ Gyeonggi-do, 16229, Republic of Korea \\ *These authors contributed equally to \\ this work
}

\begin{abstract}
Introduction: Endoplasmic reticulum (ER) stress condition is characterized as the accumulation of misfolded or unfolded proteins in lumen of ER. This condition has been implicated in various diseases and pathologies including $\beta$-cell apoptosis, Alzheimer's disease and atherosclerosis. We have reported that hydroxynaphthoic acids (HNA), naphthalene analogues of salicylic acid (SA), reduced ER stress. In this study, we explored structural modification to bi-aryl analogues of SA.
\end{abstract}

Methods: Palladium-catalyzed cross-coupling was applied to synthesize bi-aryl analogues of SA. Anti-ER stress activity was monitored by using our cell-based assay system where ER stress is induced by tunicamycin. To monitor ER stress markers, ER stress was induced physiologically relevant palmitate system.

Results: Many analogues decreased ER stress signal induced by tunicamycin. Compounds creating dihedral angle between Ar group and SA moiety generally increased the activity but gave some cytotoxicity to indicate the crucial role of flat conformation of aromatic region. The best compound (16e) showed up to almost 6-fold and 90-fold better activity than 3-HNA and tauro-ursodeoxycholic acid, positive controls, respectively. ER stress markers such as p-PERK and p-JNK were accordingly decreased in Western blotting upon treatment of 16e under palmitate-induced condition.

Conclusion: Anti-ER stress activity and toxicity profile of bi-aryl analogues of SA could provide a novel platform for potential therapy for protein misfolding diseases.

Keywords: endoplasmic reticulum stress, aryl-substituted salicylate, protein misfolding, biaryl group

\section{Introduction}

Endoplasmic reticulum (ER) plays a pivotal role in protein synthesis by accommodating proper folding to afford functionality of de novo synthesized proteins. ER can be placed under a stress condition when unfolded or misfolded peptides are accumulated inside (ER stress). Under this condition, a series of cellular events, known as unfolded protein responses (UPRs) or ER stress responses, are activated in order to manage the cellular damages. ${ }^{1}$ They involve cellular defense mechanisms such as translational attenuation, transcriptional activation of chaperones and degradation factors, ER-associated degradation (ERAD), and apoptosis. ER stress is controlled through well-documented sensor molecules residing in ER: protein kinase RNA-activated (PKR)-like ER kinase (PERK), activating transcription factor 6 (ATF6), and inositol-requiring enzyme $1 \alpha$ (IRE1 $\alpha)$. They relay on complex
Correspondence: Young-mi Kim;

Tae-gyu Nam

Tel +82-3I-400-58I5; +82-3I-400-5807

Fax +82-31-400-5958

Email ymikim12@hanyang.ac.kr;

tnam@hanyang.ac.kr 


\section{Graphical Abstract}
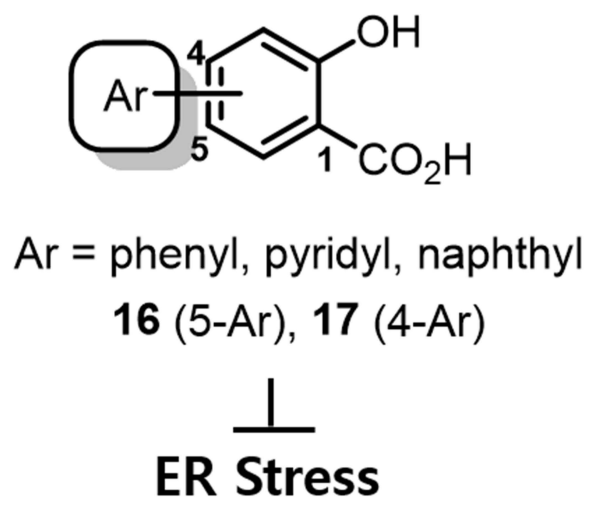

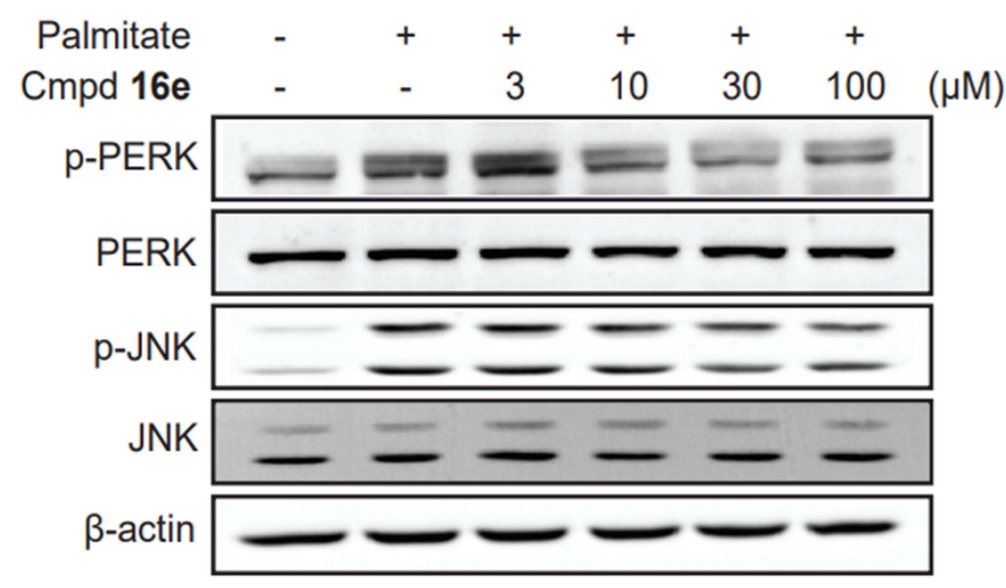

downstream signal cascade to decide either survival or apoptotic pathway. ${ }^{2}$ ER stress has been implicated in various diseases and pathologies such as Alzheimer's disease, diabetic retinopathy, atherosclerosis, type 2 diabetes, $\beta$-cell apoptosis, and lung inflammation. ${ }^{3}$ It was also demonstrated to be strongly linked with autophagy and related pathologies. $^{4}$

While chaperone molecules to ameliorate misfolded peptides/proteins are mostly peptides and proteins, there are chemical compounds that function as chaperone by reducing ER stress, known as chemical chaperones. Several chemical chaperones have been investigated as potential treatments for the ER stress-related pathologies. Most prominent examples include 4-phenyburytic acid (4-PBA), ${ }^{5}$ salubrinal, ${ }^{6}$ and tauro-ursodeoxycholic acid (t-UDCA). ${ }^{7} 4$-PBA is a histone deacetylase (HDAC) inhibitor and exerted therapeutic values against several ER stress-related conditions. ${ }^{7,8}$ Salubrinal was found to protect cells from ER stress by hampering eIF2a from dephosphorylation which is one of the hallmark events of UPR. ${ }^{6}$ $\mathrm{t}$-UDCA showed anti-ER stress activity in various contexts including type 2 diabetes, obesity and cell death. ${ }^{7,9,10}$

From a more specific point of view, pharmacological chaperones could be separated from chemical chaperones although both are typically small molecules. In this classification, pharmacological chaperones target a specific protein in UPR signaling pathway or that is responsible for misfolded protein storage to inhibit ER stress while chemical chaperones exert the activity in a rather non-specific way and consist of osmolytes and hydrophobic molecules. Representative pharmacological chaperones include iminosugars to bind to $\beta$-glucocerebrosidase as potential treatment for Gaucher disease $\mathrm{e}^{11,12}$ and STF-083010 to treat atherosclerosis as an IRE1 inhibitor. ${ }^{13}$

In search of novel chemical chaperones, we have reported that hydroxynaphthoic acids (HNAs) showed about an order of magnitude lower $\mathrm{EC}_{50}$ than known chemical chaperones such as salicylic acid ${ }^{14}$ and $\mathrm{t}-$ UDCA. $^{15}$ HNAs were identified through a cell-based assay we have developed and decreased ER stress markers including GRP78 and phosphorylated PERK. ${ }^{14,16}$ Especially, 3-Hydroxy-2-naththoic acid (3-HNA) showed excellent anti-diabetic effects including recovery of insulin sensitivity and glucose-lowering activity in ob/ob mouse when administered orally through ER stress-reducing activity. ${ }^{16}$

Structurally, 3-HNA has an extended phenyl group of salicylic acid. It is indicated that the addition of aromatic moiety to salicylic acid toward 3-HNA exerted beneficial effects on the activity. Therefore, our hypothesis was that the increased activity of 3-HNA is due to the naphthalene ring and modification of the aromatic ring of salicylic acid could further vary the activity of this scaffold (Figure 1).

To investigate our hypothesis, we explored an alternative approach to install extra aromaticity to salicylic acid. We have designed biphenyl analogues of salicylic acid instead of extending flatness from phenyl group in salicylic acid to naphthalene group in HNAs. In this study, the second Ar groups were tethered at the 4- or 5-position of salicylic acid to form biaryl moiety. It was expected that the biaryl system result in the expansion of $\pi$-electron in a sterically distinct manner from naphthalene system in 
<smiles>O=C(O)c1cc2ccccc2cc1O</smiles>

3-HNA

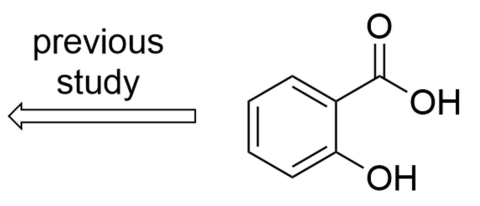

this study

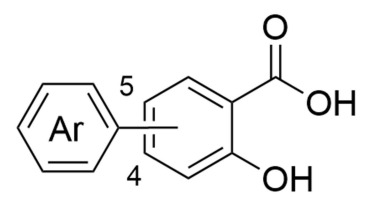

Salicylic acid

Figure I Outline of the present study.

HNAs and generate a some level of dihedral interaction between the two aromatic rings. Indeed, aryl substituted salicylates shown in this study showed better activity than the parent HNA shedding a new light on the ER stressreducing scaffold.

\section{Materials and Methods Chemistry}

Unless noted otherwise, materials were purchased from commercial suppliers and used without further purification. Air- or moisture-sensitive reactions were carried out under an inert gas atmosphere. Progress of reaction was monitored by thin-layer chromatography (TLC) using silica gel $\mathrm{F}_{254}$ plates. Purification of the products was performed by flash column chromatography using silica gel 60 (230-400 mesh) or by Biotage "Isolera One" system with indicated solvents. Melting points were determined using a Kruss melting pointer meter and were not corrected. NMR spectra were obtained using a Bruker spectrometer $400 \mathrm{MHz}$ and for ${ }^{1} \mathrm{H}-\mathrm{NMR}, 100 \mathrm{MHz}$ for ${ }^{13} \mathrm{C}-\mathrm{NMR}$, respectively. Chemical shifts $(\delta)$ were expressed in ppm using solvent as an internal standard and coupling constant $(J)$ in hertz. Mass spectra (MS) were obtained using a Waters Micromass ZQ instrument and High-resolution mass spectra (HRMS) were obtained using an Agilent Technologies Accurate Mass QTOF LC/ MS spectrometer. Mass spectra were recorded in positive ion mode with an electrospray (ESI) source.

\section{Ethyl 3-Hydroxy-2-Naphthoate (6)}

$\mathrm{H}_{2} \mathrm{SO}_{4}(0.16 \mathrm{~mL})$ was added to a solution of 3-hydroxy2-naphthoic acid (3-HNA, $565 \mathrm{mg}, 3 \mathrm{mmol}$ ) in EtOH $(30 \mathrm{~mL})$. The mixture was refluxed for 1 day. The reaction mixture was concentrated, diluted with EA, washed with $\mathrm{NaHCO}_{3}$, water, and dried over anhydrous $\mathrm{MgSO}_{4}$. The residue was purified by using silica gel chromatography (5\% EA in Hexanes) to give 6 as a yellow solid. (613 mg, $95 \%$ ) ${ }^{1} \mathrm{H}-\mathrm{NMR}$ (400 MHz, DMSO- $\left.d_{6}\right) \delta 10.35(\mathrm{~s}, 1 \mathrm{H})$, $8.50(\mathrm{~s}, 1 \mathrm{H}), 7.99(\mathrm{dd}, J=8.2,0.6 \mathrm{~Hz}, 1 \mathrm{H}), 7.78(\mathrm{dd}, J=$ 8.3, $0.5 \mathrm{~Hz}, 1 \mathrm{H}), 7.56$ (ddd, $J=8.2,6.8,1.2 \mathrm{~Hz}, 1 \mathrm{H}$ ), $7.42-7.33(\mathrm{~m}, 2 \mathrm{H}), 4.44(\mathrm{q}, J=7.1 \mathrm{~Hz}, 2 \mathrm{H}), 1.40(\mathrm{t}, J=$ $7.1 \mathrm{~Hz}, 3 \mathrm{H}) . \mathrm{R}_{\mathrm{f}}=0.9(10 \%$ EtOAc in Hex). MS (ESI) $\mathrm{m} /$ $z 217[\mathrm{M}+\mathrm{H}]^{+}$

\section{3-Hydroxy-2-Naphthamide (7)}

The mixture of $6(648 \mathrm{mg}, 3 \mathrm{mmol})$ and $28 \% \mathrm{NH}_{4} \mathrm{OH}$ $(3 \mathrm{~mL})$ was refluxed for $1 \mathrm{~h}$. The reaction mixture was diluted with $\mathrm{CH}_{2} \mathrm{Cl}_{2}$, acidified with $\mathrm{HCl}$ about $\mathrm{pH}$ 2, washed with water, brine, and dried over anhydrous $\mathrm{MgSO}_{4}$. The residue was purified by using silica gel chromatography (gradient, $1 \%$ to $2 \% \mathrm{MeOH}$ in $\mathrm{CH}_{2} \mathrm{Cl}_{2}$ ) to give 7 as a yellow solid. (103 mg, 55\%) ${ }^{1} \mathrm{H}$-NMR (400 MHz, DMSO- $\left.d_{6}\right) \delta 12.50(\mathrm{~s}, 1 \mathrm{H}), 8.64(\mathrm{~s}, 1 \mathrm{H}), 8.56(\mathrm{~s}$, $1 \mathrm{H}), 8.06(\mathrm{~s}, 1 \mathrm{H}), 7.83(\mathrm{~d}, J=8.2 \mathrm{~Hz}, 1 \mathrm{H}), 7.75(\mathrm{~d}, J=7.9$ $\mathrm{Hz}, 1 \mathrm{H}), 7.52$ (ddd, $J=8.2,6.8,1.2 \mathrm{~Hz}, 1 \mathrm{H}), 7.36$ (ddd, $J=8.1,6.8,1.2 \mathrm{~Hz}, 1 \mathrm{H}), 7.26(\mathrm{~s}, 1 \mathrm{H}) . \mathrm{R}_{\mathrm{f}}=0.7(5 \% \mathrm{MeOH}$ in $\mathrm{CH}_{2} \mathrm{Cl}_{2}$ ). MS (ESI) $\mathrm{m} / z 188[\mathrm{M}+\mathrm{H}]^{+}$

\section{3-Hydroxy-2-Naphthonitrile (8)}

Phosphoryl chloride $(0.025 \mathrm{~mL}, 0.26 \mathrm{mmol})$ was added to $7(38 \mathrm{mg}, 0.2 \mathrm{mmol})$ in DMF (1 mL) at rt. After stirred for $0.5 \mathrm{~h}$, the mixture was stirred at $0{ }^{\circ} \mathrm{C}$. The reaction mixture was washed with $\mathrm{NaHCO}_{3}$, water, and dried over anhydrous $\mathrm{MgSO}_{4}$. The residue was purified by using silica gel chromatography (20\% EA in Hexanes) to give 8 as a yellow solid (46mg, 100\%). ${ }^{1} \mathrm{H}-\mathrm{NMR}(400 \mathrm{MHz}$, DMSO- $\left.d_{6}\right) \delta 11.11(\mathrm{~s}, 1 \mathrm{H}), 8.44(\mathrm{~s}, 1 \mathrm{H}), 7.90(\mathrm{~d}, J=7.7$ $\mathrm{Hz}, 1 \mathrm{H}), 7.80$ (d, $J=7.9 \mathrm{~Hz}, 1 \mathrm{H}), 7.57$ (ddd, $J=8.2,6.8$, $1.2 \mathrm{~Hz}, 1 \mathrm{H}$ ), 7.41 (ddd, $J=8.1,6.9,1.1 \mathrm{~Hz}, 1 \mathrm{H}), 7.33$ (s, $1 \mathrm{H}) . \mathrm{R}_{\mathrm{f}}=0.4\left(2 \% \mathrm{MeOH}\right.$ in $\left.\mathrm{CH}_{2} \mathrm{Cl}_{2}\right)$. MS (ESI) $m / z 170$ $[\mathrm{M}+\mathrm{H}]^{+}$

\section{3-(IH-Tetrazol-2-YI)naphthalen-2-OI (I)}

The mixture of $8(44 \mathrm{mg}, 0.26 \mathrm{mmol})$, sodium azide (26 $\mathrm{mg}, 0.4 \mathrm{mmol}$ ), trimethylamine- $\mathrm{HCl}$ and toluene was heated to $95{ }^{\circ} \mathrm{C}$ for overnight. After cooling, the product was extracted with water. The aqueous layer, 
$36 \% \mathrm{HCl}$ was added dropwised to salt out the product tetrazole. After filtration, the solid was dried under reduced pressure to give 1 as a white solid (46 mg, 83\%). ${ }^{1} \mathrm{H}-\mathrm{NMR}\left(400 \mathrm{MHz}, \mathrm{DMSO}-d_{6}\right) \delta 16.17(\mathrm{~s}, 1 \mathrm{H})$, $11.16(\mathrm{~s}, 1 \mathrm{H}), 8.66(\mathrm{~s}, 1 \mathrm{H}), 8.00(\mathrm{~d}, J=7.8 \mathrm{~Hz}, 1 \mathrm{H}), 7.80$ $(\mathrm{d}, J=7.9 \mathrm{~Hz}, 1 \mathrm{H}), 7.56-7.49(\mathrm{~m}, 1 \mathrm{H}), 7.44-7.35(\mathrm{~m}$, 2H). ${ }^{13} \mathrm{C}-\mathrm{NMR}\left(101 \mathrm{MHz}, \mathrm{DMSO}-d_{6}\right) \delta 152.17(\mathrm{~s})$, 151.63 (s), 135.48 (s), 129.97 (s), 128.55 (s), 128.01 (s), $127.20 \quad(\mathrm{~s}), 125.90 \quad(\mathrm{~s}), 123.87 \quad(\mathrm{~s}), 113.41 \quad(\mathrm{~s})$, 109.90 (s), 40.09 (s), 39.88 (s), 39.67 (s), 39.46 (s), 39.25 (s), $39.04(\mathrm{~s}), 38.83$ (s). $\mathrm{R}_{\mathrm{f}}=0.2(20 \% \mathrm{MeOH}$ in $\mathrm{CH}_{2} \mathrm{Cl}_{2}$ ). mp: $255 \sim 257{ }^{\circ} \mathrm{C}$ dec. MS (ESI) $\mathrm{m} / z 213[\mathrm{M}+$ $\mathrm{H}]^{+}$. HRMS $[\mathrm{M}+\mathrm{H}]^{+} \mathrm{C}_{11} \mathrm{H}_{9} \mathrm{~N}_{4} \mathrm{O}$ cald 213.0771 Found 213.0775.

\section{General Procedure for the Synthesis of 12 and 13}

$\mathrm{H}_{2} \mathrm{SO}_{4}(0.5 \mathrm{~mL})$ was added to a solution of 5-iodosalicylic acid 10 or 4-ioidosalicylic acid $11(4 \mathrm{mmol})$ in $\mathrm{EtOH}$ $(17 \mathrm{~mL})$. The mixture was refluxed for 1 day. The reaction mixture was concentrated, diluted with ethyl acetate (EA), washed with $\mathrm{NaHCO}_{3}$, water, and dried over anhydrous $\mathrm{MgSO}_{4}$. The residue was purified by using silica gel chromatography (7\% 10\% EA in Hexanes) to give 12 or 13 .

\section{Ethyl 2-Hydroxy-5-lodobenzoate (I2)}

White solid. Yield: $66 \%$; ${ }^{1} \mathrm{H}-\mathrm{NMR}\left(400 \mathrm{MHz}, \mathrm{CDCl}_{3}\right) \delta$ $10.82(\mathrm{~s}, 1 \mathrm{H}), 8.12(\mathrm{~d}, J=2.3 \mathrm{~Hz}, 1 \mathrm{H}), 7.68(\mathrm{dd}, J=8.8$, $2.3 \mathrm{~Hz}, 1 \mathrm{H}), 6.76(\mathrm{~d}, J=8.8 \mathrm{~Hz}, 1 \mathrm{H}), 4.41(\mathrm{q}, J=7.1 \mathrm{~Hz}$, $2 \mathrm{H}), 1.42(\mathrm{t}, J=7.1 \mathrm{~Hz}, 3 \mathrm{H}) . \mathrm{R}_{\mathrm{f}}=0.8(10 \%$ EtOAc in Hex). MS (ESI) $m / z 292.9[\mathrm{M}+\mathrm{H}]^{+}$[CAS 15125-84-5]

\section{Ethyl 2-Hydroxy-4-lodobenzoate (I3)}

Yield: 62\%; yellow liquid; ${ }^{1} \mathrm{H}-\mathrm{NMR}\left(400 \mathrm{MHz}, \mathrm{CDCl}_{3}\right) \delta$ 10.77 (s, 1H), 7.44 (d, $J=8.4 \mathrm{~Hz}, 1 \mathrm{H}), 7.33$ (d, $J=1.6 \mathrm{~Hz}$, $1 \mathrm{H}), 7.16(\mathrm{dd}, J=8.4,1.7 \mathrm{~Hz}, 1 \mathrm{H}), 4.33(\mathrm{q}, J=7.1 \mathrm{~Hz}$, $2 \mathrm{H}), 1.34(\mathrm{t}, J=7.1 \mathrm{~Hz}, 3 \mathrm{H}) . \mathrm{R}_{\mathrm{f}}=0.6(33 \%$ EtOAc in Hex). MS (ESI) $m / z 292.9$ [M+H] ${ }^{+}$[CAS 730977-57-8]

\section{General Procedure for the Synthesis of}

\section{$14 \mathrm{a}, 14 \mathrm{c}, 14 \mathrm{~d}$ and $15 \mathrm{a}, 15 \mathrm{c}$, I5d}

Arylboronic acid or corresponding boronic ester (9) (0.3 mmol), $\mathrm{Pd}\left(\mathrm{PPh}_{3}\right)_{4}(0.01 \sim 0.02 \mathrm{mmol})$, and $2 \mathrm{~N} \mathrm{Na}_{2} \mathrm{CO}_{3}$ $(0.6 \mathrm{~mL})$ were added to a solution of 12 or $13(0.2 \mathrm{mmol})$ in EtOH $(0.4 \mathrm{~mL})$ and toluene $(1.6 \mathrm{~mL})$. The mixture was refluxed for $5 \mathrm{hr}$ under argon. The reaction mixture was diluted with water, neutralized to $\mathrm{pH} 7 \sim 8$ with sat. $\mathrm{NH}_{4} \mathrm{Cl}$, and extracted with ethyl acetate. The organic layer was combined, dried over anhydrous $\mathrm{MgSO}_{4}$ and concentrated under reduced pressure. The residue was purified by using silica gel chromatography (5\% 20\% EA in Hexanes) to give $14 \mathrm{a}, 14 \mathrm{c}, 14 \mathrm{~d}, 15 \mathrm{a}, 15 \mathrm{c}, 15 \mathrm{~d}$.

\section{Ethyl 4-Hydroxy-[I, I'-Biphenyl] -3-Carboxylate (I4a)}

Yellow liquid. Yield: 74\%. ${ }^{1} \mathrm{H}-\mathrm{NMR}\left(400 \mathrm{MHz}, \mathrm{CDCl}_{3}\right) \delta$ 10.81 (s, 1H), 8.02-7.98 (m, 1H), 7.63 (dd, $J=8.6,2.4$ $\mathrm{Hz}, 1 \mathrm{H}), 7.51-7.46(\mathrm{~m}, 2 \mathrm{H}), 7.41-7.33(\mathrm{~m}, 2 \mathrm{H}), 7.27(\mathrm{dt}$, $J=9.3,4.3 \mathrm{~Hz}, 1 \mathrm{H}), 7.02-6.97(\mathrm{~m}, 1 \mathrm{H}), 4.38(\mathrm{q}, J=7.1$ $\mathrm{Hz}, 2 \mathrm{H}), 1.37$ (t, $J=7.1 \mathrm{~Hz}, 3 \mathrm{H}) . \mathrm{R}_{\mathrm{f}}=0.5(6.25 \%$ EtOAc in Hex). MS m/z $244[\mathrm{M}+\mathrm{H}]^{+}$[CAS 17504-14-2]

\section{Ethyl 2-Hydroxy-5-(Pyridin-4-YI)benzoate (I 4c)}

Yellow solid. Yield: $39 \% .{ }^{1} \mathrm{H}-\mathrm{NMR}\left(400 \mathrm{MHz}, \mathrm{CDCl}_{3}\right) \delta$ $11.30(\mathrm{~s}, 1 \mathrm{H}), 8.70$ (d, $J=5.8 \mathrm{~Hz}, 2 \mathrm{H}), 8.26$ (d, $J=2.4 \mathrm{~Hz}$, 1H), 7.99 (d, $J=6.1 \mathrm{~Hz}, 2 \mathrm{H}), 7.83(\mathrm{dd}, J=8.8,2.4 \mathrm{~Hz}$, $1 \mathrm{H}), 7.16(\mathrm{~d}, J=8.8 \mathrm{~Hz}, 1 \mathrm{H}), 4.45(\mathrm{q}, J=7.1 \mathrm{~Hz}, 2 \mathrm{H})$, $1.42(\mathrm{t}, J=7.1 \mathrm{~Hz}, 3 \mathrm{H}) ;{ }^{13} \mathrm{C}-\mathrm{NMR}\left(100 \mathrm{MHz}\right.$, DMSO- $\left.d_{6}\right)$ $\delta 168.29$ (s), 160.64 (s), 150.23 (s), 145.66 (s), 133.63 (s), 128.14 (d, $J=4.1 \mathrm{~Hz}), 120.58$ (s), 118.40 (s), 114.19 (s), $61.53(\mathrm{~s}), 14.00(\mathrm{~s}) . \mathrm{R}_{\mathrm{f}}=0.2$ (33\% EtOAc in Hex); mp: 100 105 ${ }^{\circ} \mathrm{C}$. MS (ESI) $\mathrm{m} / z 244[\mathrm{M}+\mathrm{H}]^{+}$. HRMS $[\mathrm{M}+\mathrm{H}]^{+}$ $\mathrm{C}_{14} \mathrm{H}_{14} \mathrm{NO}_{3}$ calcd for 244.0968 found 244.0962 .

\section{Ethyl 2-Hydroxy-5-(Pyridin-3-YI)benzoate (I4d)}

Brown solid. Yield: $88 \%$. ${ }^{1} \mathrm{H}-\mathrm{NMR}\left(400 \mathrm{MHz}, \mathrm{CDCl}_{3}\right) \delta$ $11.14(\mathrm{~s}, 1 \mathrm{H}), 8.92(\mathrm{~s}, 1 \mathrm{H}), 8.64(\mathrm{~d}, J=5.1 \mathrm{~Hz}, 1 \mathrm{H}), 8.50$ (d, $J=7.8 \mathrm{~Hz}, 1 \mathrm{H}), 8.09$ (d, $J=2.3 \mathrm{~Hz}, 1 \mathrm{H}), 7.93$ (dd, $J=$ $7.9,5.4 \mathrm{~Hz}, 1 \mathrm{H}), 7.67(\mathrm{dd}, J=8.7,2.3 \mathrm{~Hz}, 1 \mathrm{H}), 7.14(\mathrm{~d}, J=$ $8.7 \mathrm{~Hz}, 1 \mathrm{H}), 4.44(\mathrm{q}, J=7.1 \mathrm{~Hz}, 2 \mathrm{H}), 1.42(\mathrm{t}, J=7.1 \mathrm{~Hz}$, $3 \mathrm{H}) ;{ }^{13} \mathrm{C}-\mathrm{NMR}\left(101 \mathrm{MHz}, \mathrm{DMSO}-d_{6}\right) \delta 168.43(\mathrm{~s}), 159.95$ (s), 147.68 (s), 146.76 (s), 134.63 (s), 134.23 (s), 133.89 (s), $128.11(\mathrm{~d}, J=2.1 \mathrm{~Hz}), 124.05(\mathrm{~s}), 118.34(\mathrm{~s}), 114.09$ (s), 61.49 (s), 13.99 (s). $\mathrm{R}_{\mathrm{f}}=0.3$ (33\% EtOAc in Hex). mp: $84 \sim 86.5{ }^{\circ} \mathrm{C}$. MS (ESI) $\mathrm{m} / z 244[\mathrm{M}+\mathrm{H}]^{+}$. HRMS [M+H] $\mathrm{C}_{14} \mathrm{H}_{14} \mathrm{NO}_{3}$ calcd for 244.0968 found 244.0960 .

\section{Ethyl 3-Hydroxy-[I, I'-Biphenyl] -4-Carboxylate (I5a)}

Yellow solid. Yield: $82 \%$. ${ }^{1} \mathrm{H}-\mathrm{NMR}\left(400 \mathrm{MHz}, \mathrm{CDCl}_{3}\right) \delta$ 10.84 (s, 1H), 7.84 (d, $J=8.3 \mathrm{~Hz}, 1 \mathrm{H}), 7.54$ (ddd, $J=4.4$, $3.5,1.9 \mathrm{~Hz}, 2 \mathrm{H}), 7.41-7.36(\mathrm{~m}, 2 \mathrm{H}), 7.34$ (dd, $J=5.0,3.6$ 
$\mathrm{Hz}, 1 \mathrm{H}), 7.14(\mathrm{~d}, J=1.7 \mathrm{~Hz}, 1 \mathrm{H}), 7.06(\mathrm{dd}, J=8.3,1.8$ $\mathrm{Hz}, 1 \mathrm{H}), 4.36$ (q, $J=7.1 \mathrm{~Hz}, 2 \mathrm{H}), 1.37$ (t, $J=7.1 \mathrm{~Hz}, 3 \mathrm{H}$ ). $\mathrm{R}_{\mathrm{f}}=0.5\left(6 \%\right.$ EtOAc in Hex). MS $m / z 243[\mathrm{M}+\mathrm{H}]^{+}$[CAS 148066-43-7]

\section{Ethyl 2-Hydroxy-4-(Pyridin-4-yl)benzoate (I5c)}

Yellow solid. Yield: $88 \%$. ${ }^{1} \mathrm{H}-\mathrm{NMR}\left(400 \mathrm{MHz}, \mathrm{CDCl}_{3}\right)$ $\delta 11.00(\mathrm{~s}, 1 \mathrm{H}), 8.79(\mathrm{~d}, J=5.4 \mathrm{~Hz}, 2 \mathrm{H}), 8.04(\mathrm{~d}, J=$ $5.4 \mathrm{~Hz}, 2 \mathrm{H}), 8.01(\mathrm{~d}, J=8.2 \mathrm{~Hz}, 1 \mathrm{H}), 7.29(\mathrm{~d}, J=1.1$ $\mathrm{Hz}, 1 \mathrm{H}), 7.18(\mathrm{~d}, J=8.3 \mathrm{~Hz}, 1 \mathrm{H}), 4.42(\mathrm{q}, J=7.1 \mathrm{~Hz}$, 2H), $1.40(\mathrm{t}, J=7.1 \mathrm{~Hz}, 3 \mathrm{H}) ;{ }^{13} \mathrm{C}-\mathrm{NMR}(100 \mathrm{MHz}$, DMSO- $\left.d_{6}\right) \delta 168.46(\mathrm{~s}), 160.45(\mathrm{~s}), 150.12(\mathrm{~s}), 145.71$ (s), $143.84(\mathrm{~s}), 130.83(\mathrm{~s}), 121.50(\mathrm{~s}), 117.88(\mathrm{~s}), 115.51$ (s), $113.61(\mathrm{~s}), 61.50(\mathrm{~s}), 13.98(\mathrm{~s}) \cdot \mathrm{R}_{\mathrm{f}}=0.3(33 \%$ EtOAc in Hex). mp: $71 \sim 74{ }^{\circ} \mathrm{C}$. MS (ESI) $\mathrm{m} / \mathrm{z} 244$ [M $+\mathrm{H}]^{+}$; HRMS $[\mathrm{M}+\mathrm{H}]^{+} \mathrm{C}_{14} \mathrm{H}_{14} \mathrm{NO}_{3}$ calcd for 244.0968 found 244.0963 .

\section{Ethyl 2-Hydroxy-4-(Pyridin-3-YI)benzoate (I5d)}

Yellow solid. Yield: $78 \%$. ${ }^{1} \mathrm{H}-\mathrm{NMR}\left(400 \mathrm{MHz}, \mathrm{CDCl}_{3}\right) \delta$ $11.00(\mathrm{~s}, 1 \mathrm{H}), 8.97(\mathrm{~s}, 1 \mathrm{H}), 8.75(\mathrm{~d}, J=4.9 \mathrm{~Hz}, 1 \mathrm{H}), 8.54$ (d, $J=7.8 \mathrm{~Hz}, 1 \mathrm{H}), 8.03-7.96(\mathrm{~m}, 2 \mathrm{H}), 7.18(\mathrm{~d}, J=1.3$ $\mathrm{Hz}, 1 \mathrm{H}), 7.08$ (dd, $J=8.2,1.4 \mathrm{~Hz}, 1 \mathrm{H}), 4.42(\mathrm{t}, J=7.1 \mathrm{~Hz}$, 2H), 1.39 (t, $J=7.1 \mathrm{~Hz}, 3 \mathrm{H}) ;{ }^{13} \mathrm{C}-\mathrm{NMR}(100 \mathrm{MHz}$, DMSO- $\left.d_{6}\right) \delta 168.65(\mathrm{~s}), 160.55(\mathrm{~s}), 149.08(\mathrm{~s}), 147.40$ (s), 143.80 (s), 134.98 (s), 134.20 (s), 130.73 (s), 124.11 (s), 117.99 (s), 115.39 (s), 112.60 (s), 61.45 (s), 13.99 (s); $\mathrm{R}_{\mathrm{f}}=0.4$ (33\% EtOAc in Hex). mp: $162 \sim 164{ }^{\circ} \mathrm{C}$ (dec.). MS (ESI) $m / z 244[\mathrm{M}+\mathrm{H}]^{+}$. HRMS [M+H] ${ }^{+} \mathrm{C}_{14} \mathrm{H}_{14} \mathrm{NO}_{3}$ calcd for 244.0963 found 244.0960 .

\section{Ethyl 2-Hydroxy-5-(Naphthalen-I-YI) benzoate (I4b)}

Naphthaleneboronic acid (301 mg, $1.75 \mathrm{mmol}), \mathrm{Pd}\left(\mathrm{PPh}_{3}\right)_{4}$ (67 mg, $0.06 \mathrm{mmol}$ ), aqueous $2 \mathrm{~N} \mathrm{Na}_{2} \mathrm{CO}_{3}(4.7 \mathrm{~mL}$ ) was added to a solution of ethyl 2-hydroxy-5-iodobenzoate (341 $\mathrm{mg}, 1.17 \mathrm{mmol})$ in EtOH $(6 \mathrm{~mL})$ and toluene $(6 \mathrm{~mL})$. The mixture was refluxed for $7 \mathrm{~h}$ under argon gas. The reaction mixture was diluted with water and acidified to $\mathrm{pH} 7-8$ with $\mathrm{NH}_{4} \mathrm{Cl}$. The crude was extraction by EA. The residue was purified by using silica gel chromatography (100\% Hexanes) to give $14 \mathrm{~b}$ as a white solid. (249 mg, y. 73\%). ${ }^{1} \mathrm{H}-\mathrm{NMR}\left(400 \mathrm{MHz}, \mathrm{CDCl}_{3}\right) \delta 10.96$ (s, $1 \mathrm{H}), 7.99(\mathrm{~d}, J=2.2 \mathrm{~Hz}, 1 \mathrm{H}), 7.92(\mathrm{dd}, J=8.3,1.1 \mathrm{~Hz}$, 1H), 7.90-7.81 (m, 2H), 7.60 (dd, $J=8.4,2.3 \mathrm{~Hz}, 1 \mathrm{H})$,
7.57-7.38 (m, 4H), $7.12(\mathrm{~d}, J=8.5 \mathrm{~Hz}, 1 \mathrm{H}), 4.42(\mathrm{q}, J=$ $7.1 \mathrm{~Hz}, 2 \mathrm{H}), 1.39(\mathrm{t}, J=7.1 \mathrm{~Hz}, 3 \mathrm{H})) ;{ }^{13} \mathrm{C}-\mathrm{NMR}(100$ $\left.\mathrm{MHz}, \mathrm{CDCl}_{3}\right) \delta 170.28(\mathrm{~s}), 161.06(\mathrm{~s}), 139.00(\mathrm{~s}), 137.31$ (s), $133.86(\mathrm{~s}), 131.76$ (d, $J=3.9 \mathrm{~Hz}), 131.06$ (s), 128.40 (s), 127.79 (s), 127.03 (s), 126.22 (s), 125.82 (d, $J=14.4$ $\mathrm{Hz}), 125.42$ (s), 117.50 (s), 112.57 (s), 61.58 (s), 14.21 (s); $\mathrm{R}_{\mathrm{f}}=0.3\left(100 \%\right.$ Hex); mp: 79 82.5 ${ }^{\circ} \mathrm{C}$; MS (ESI) $\mathrm{m} / z 293$ $[\mathrm{M}+\mathrm{H}]^{+}$

\section{General Procedure for the Synthesis of} $16 a, 16 c, 16 d$ or $17 a \sim 17 d$

Lithium hydroxide monohydrate $(3 \mathrm{mmol})$ was added to a solution of ethyl ester $14 \mathrm{a} \sim 14 \mathrm{~d}$ or $15 \mathrm{a}, 15 \mathrm{c}, 15 \mathrm{~d}(0.15$ $\mathrm{mmol})$ in EtOH $(2 \mathrm{~mL})$. The mixture was refluxed for 12 h. The reaction mixture was concentrated, diluted with water, and washed with ethyl acetate. The aqueous phase was acidified to $\mathrm{pH} 2$ with $5 \% \mathrm{HCl}$ and extracted with ethyl acetate. Combined organic layer was concentrated under reduced pressure and the residue was purified by using silica gel chromatography $\left(10 \% \mathrm{MeOH}\right.$ in $\left.\mathrm{CH}_{2} \mathrm{Cl}_{2}\right)$ to give $16 \mathrm{a} \sim 16 \mathrm{~d}$ or $17 \mathrm{a}, 17 \mathrm{c}, 17 \mathrm{~d}$.

\section{4-Hydroxy-[I, I'-Biphenyl]-3-Carboxylic Acid (16a)}

Brown solid. Yield: $68 \% .{ }^{1} \mathrm{H}-\mathrm{NMR}$ (400 MHz, DMSO- $d_{6}$ ) $\delta 14.07(\mathrm{~s}, 1 \mathrm{H}), 11.36(\mathrm{~s}, 1 \mathrm{H}), 8.05$ (d, $J=2.4 \mathrm{~Hz}, 2 \mathrm{H})$, 7.85 (dd, $J=8.6,2.5 \mathrm{~Hz}, 2 \mathrm{H}), 7.67-7.61(\mathrm{~m}, 4 \mathrm{H}), 7.50$ $7.43(\mathrm{~m}, 4 \mathrm{H}), 7.39-7.32(\mathrm{~m}, 2 \mathrm{H}), 7.08(\mathrm{~d}, J=8.6 \mathrm{~Hz}, 2 \mathrm{H})$. $\mathrm{R}_{\mathrm{f}}=0.1\left(10 \% \mathrm{MeOH}\right.$ in $\left.\mathrm{CH}_{2} \mathrm{Cl}_{2}\right)$. MS $m / z 215[\mathrm{M}+\mathrm{H}]^{+}$ [CAS 323-87-5]

\section{2-Hydroxy-5-(Naphthalen-I-YI)benzoic Acid (16b)}

Brown solid. Yield: $81.2 \%$. ${ }^{1} \mathrm{H}-\mathrm{NMR} \quad(400 \mathrm{MHz}$, $\left.\mathrm{MeOH}-d_{4}\right) \delta 7.97(\mathrm{~d}, J=2.3 \mathrm{~Hz}, 1 \mathrm{H}), 7.93-7.88(\mathrm{~m}$, $1 \mathrm{H}), 7.85(\mathrm{~d}, J=8.2 \mathrm{~Hz}, 2 \mathrm{H}), 7.54-7.46(\mathrm{~m}, 3 \mathrm{H}), 7.45-$ $7.40(\mathrm{~m}, 1 \mathrm{H}), 7.38(\mathrm{dd}, J=7.0,1.1 \mathrm{~Hz}, 1 \mathrm{H}), 7.02(\mathrm{~d}$, $J=8.4 \mathrm{~Hz}, 1 \mathrm{H}) ;{ }^{13} \mathrm{C}-\mathrm{NMR}\left(100 \mathrm{MHz}, \mathrm{DMSO}-d_{6}\right) \delta$ 171.71 (s), 160.47 (s), 138.22 (s), 136.87 (s), 133.46 (s), 131.19-130.68 (m), $128.41(\mathrm{~s}), 127.63(\mathrm{~s}), 126.92(\mathrm{~s})$, 126.46 (s), 125.95 (s), 125.59 (s), 124.98 (s), 117.33 (s), $113.08(\mathrm{~s}) ; \mathrm{R}_{\mathrm{f}}=0.4\left(10 \% \mathrm{MeOH}\right.$ in $\left.\mathrm{CH}_{2} \mathrm{Cl}_{2}\right)$. mp: 231 233.7 ${ }^{\circ} \mathrm{C} \quad$ (dec.). MS (ESI) $\mathrm{m} / z \quad 265 \quad[\mathrm{M}+\mathrm{H}]^{+}$. HRMS $[\mathrm{M}+\mathrm{H}]^{+} \mathrm{C}_{17} \mathrm{H}_{13} \mathrm{O}_{3}$ calcd for 265.0783 found 265.0790 . 


\section{2-Hydroxy-5-(Pyridin-4-YI)benzoic Acid (16c)}

Yellow solid. Yield: $100 \%$. ${ }^{1} \mathrm{H}-\mathrm{NMR} \quad(400 \mathrm{MHz}$, DMSO- $\left.d_{6}\right) \delta 14.07(\mathrm{~s}, 1 \mathrm{H}), 11.36(\mathrm{~s}, 1 \mathrm{H}), 8.05$ (d, $J=$ $2.4 \mathrm{~Hz}, 1 \mathrm{H}), 7.85(\mathrm{dd}, J=8.6,2.5 \mathrm{~Hz}, 1 \mathrm{H}), 7.67-7.61$ (m, 2H), 7.50-7.43 (m, 2H), 7.39-7.32 (m, 1H), 7.08 (d, $J=$ $8.6 \mathrm{~Hz}, 1 \mathrm{H}) ;{ }^{13} \mathrm{C}-\mathrm{NMR}\left(100 \mathrm{MHz}, \mathrm{DMSO}-d_{6}\right) \delta 171.05$ (s), 164.25 (s), 149.77 (s), 147.22 (s), 130.71 (s), 128.44 (s), 124.88 (s), 120.13 (s), 119.28 (s), 117.28 (s). $\mathrm{R}_{\mathrm{f}}=0.1$ (10\% $\mathrm{MeOH}$ in $\mathrm{CH}_{2} \mathrm{Cl}_{2}$ ); mp: $340 \sim 345{ }^{\circ} \mathrm{C}$ (dec.). $\mathrm{MS}$ (ESI) $m / z 216 \quad[\mathrm{M}+\mathrm{H}]^{+}$. HRMS $[\mathrm{M}+\mathrm{H}]^{+} \quad \mathrm{C}_{12} \mathrm{H}_{10} \mathrm{NO}_{3}$ calcd for 126.0655 found 126.0648 .

\section{2-Hydroxy-5-(Pyridin-3-YI)benzoic Acid (16d)}

Yellow solid. Yield: 99\%; ${ }^{1} \mathrm{H}-\mathrm{NMR}$ (400 MHz, DMSO- $d_{6}$ ) $\delta 11.92(\mathrm{~s}, 1 \mathrm{H}), 8.83-8.78(\mathrm{~m}, 1 \mathrm{H}), 8.47(\mathrm{dd}, J=4.7,1.6$ $\mathrm{Hz}, 1 \mathrm{H}), 8.03$ (d, $J=2.6 \mathrm{~Hz}, 1 \mathrm{H}), 7.99-7.94(\mathrm{~m}, 1 \mathrm{H}), 7.56$ $(\mathrm{dd}, J=8.4,2.6 \mathrm{~Hz}, 1 \mathrm{H}), 7.45-7.39$ (m, 1H), 6.77 (d, $J=$ $8.4 \mathrm{~Hz}, 1 \mathrm{H}) . \mathrm{R}_{\mathrm{f}}=0.1\left(10 \% \mathrm{MeOH}\right.$ in $\left.\mathrm{CH}_{2} \mathrm{Cl}_{2}\right)$. MS $m /$ $z 216[\mathrm{M}+\mathrm{H}]^{+}$[CAS 23380-76-9].

\section{3-Hydroxy-[I, I'-Biphenyl]-4-Carboxylic Acid (17a)}

Brown solid. Yield: $54 \%$; ${ }^{1} \mathrm{H}-\mathrm{NMR}$ (400 MHz, DMSO- $d_{6}$ ) $\delta 11.92(\mathrm{~s}, 1 \mathrm{H}), 7.86(\mathrm{~d}, J=8.6 \mathrm{~Hz}, 1 \mathrm{H}), 7.71(\mathrm{~d}, J=7.3$ $\mathrm{Hz}, 2 \mathrm{H}), 7.48$ (t, $J=7.4 \mathrm{~Hz}, 2 \mathrm{H}), 7.44-7.38(\mathrm{~m}, 1 \mathrm{H}), 7.23$ $(\mathrm{dd}, J=3.9,2.5 \mathrm{~Hz}, 2 \mathrm{H}) . \mathrm{R}_{\mathrm{f}}=0.1\left(10 \% \mathrm{MeOH}\right.$ in $\left.\mathrm{CH}_{2} \mathrm{Cl}_{2}\right)$ . MS $m / z 215[\mathrm{M}+\mathrm{H}]^{+}$[CAS 4482-27-3].

\section{2-Hydroxy-4-(Pyridin-4-YI)benzoic Acid (I7c)}

Yellow solid. Yield: 99\%. ${ }^{1} \mathrm{H}-\mathrm{NMR}\left(400 \mathrm{MHz}\right.$, DMSO- $\left.d_{6}\right)$ $\delta 12.01(\mathrm{~s}, 1 \mathrm{H}), 8.61(\mathrm{~d}, J=6.0 \mathrm{~Hz}, 2 \mathrm{H}), 7.80(\mathrm{~d}, J=7.8$ $\mathrm{Hz}, 1 \mathrm{H}), 7.68(\mathrm{dd}, J=4.5,1.6 \mathrm{~Hz}, 2 \mathrm{H}), 7.10-7.00(\mathrm{~m}$, $2 \mathrm{H}) . \mathrm{R}_{\mathrm{f}}=0.2\left(20 \% \mathrm{MeOH}\right.$ in $\left.\mathrm{CH}_{2} \mathrm{Cl}_{2}\right)$. MS $m / z 216[\mathrm{M}$ $+\mathrm{H}]^{+}$[CAS 222986-83-6].

\section{2-Hydroxy-4-(Pyridin-3-YI)benzoic Acid (I7)}

White solid. Yield: $89 \% ;{ }^{1} \mathrm{H}$ NMR (400 MHz, DMSO- $\left.d_{6}\right) \delta$ $11.97(\mathrm{~s}, 1 \mathrm{H}), 8.89(\mathrm{~s}, 1 \mathrm{H}), 8.58(\mathrm{~d}, J=3.7 \mathrm{~Hz}, 1 \mathrm{H}), 8.12-8.02$ (m, 1H), $7.82(\mathrm{~d}, J=7.9 \mathrm{~Hz}, 1 \mathrm{H}), 7.48(\mathrm{dd}, J=7.9,4.8 \mathrm{~Hz}$, 1H), 7.11-7.01 (m, 2H); ${ }^{13} \mathrm{C}-\mathrm{NMR}$ (100 MHz, DMSO- $\left.d_{6}\right) \delta$ 171.63 (s), 161.52 (s), 149.36 (s), 147.74 (s), 143.90 (s), 134.56 (s), 134.25 (s), 131.03 (s), 123.96 (s), 117.72 (s),
115.07 (s), 112.69 (s). $\mathrm{R}_{\mathrm{f}}=0.1\left(10 \% \mathrm{MeOH}\right.$ in $\left.\mathrm{CH}_{2} \mathrm{Cl}_{2}\right)$. mp: $266.5 \sim 268.7{ }^{\circ} \mathrm{C}$ (dec.). MS (ESI) $\mathrm{m} / z 216[\mathrm{M}+\mathrm{H}]^{+}$; HRMS $[\mathrm{M}+\mathrm{H}]^{+} \quad \mathrm{C}_{12} \mathrm{H}_{10} \mathrm{NO}_{3}$ calcd for 126.0655 found 126.0659 .

\section{2-Hydroxy-4-(Naphthalen-I-YI)benzoic Acid (I7b)}

1-Naphthaleneboronic acid (52 mg, $0.3 \mathrm{mmol}), \mathrm{Pd}\left(\mathrm{PPh}_{3}\right)_{4}$ (12 $\mathrm{mg}, 0.01 \mathrm{mmol})$, aqueous $2 \mathrm{~N} \mathrm{Na}_{2} \mathrm{CO}_{3}(0.8 \mathrm{~mL})$ was added to a solution of 2-hydroxy-4-iodobenzoic acid (11, $53 \mathrm{mg}, 0.2 \mathrm{mmol})$ in EtOH $(2 \mathrm{~mL})$, toluene $(8 \mathrm{~mL})$. The mixture was refluxed for $5 \mathrm{~h}$ under argon gas. The reaction mixture was diluted with water and acidified to $\mathrm{pH} 2$ with $5 \% \mathrm{HCl}$. The crude was extraction by ethyl acetate. The residue was purified by using silica gel chromatography $\left(10 \% \mathrm{MeOH}\right.$ in $\left.\mathrm{CH}_{2} \mathrm{Cl}_{2}\right)$ to give $17 \mathrm{~b}$ as a brown solid (41 mg, y. 77.5\%). ${ }^{1} \mathrm{H}-\mathrm{NMR}\left(400 \mathrm{MHz}\right.$, DMSO- $\left.d_{6}\right) \delta$ $12.52(\mathrm{~s}, 1 \mathrm{H}), 8.01(\mathrm{dd}, J=13.9,5.4 \mathrm{~Hz}, 2 \mathrm{H}), 7.95-7.89$ (m, $1 \mathrm{H}), 7.83(\mathrm{~d}, J=8.2 \mathrm{~Hz}, 1 \mathrm{H}), 7.62-7.50(\mathrm{~m}, 3 \mathrm{H}), 7.47$ (dd, $J=7.0,1.0 \mathrm{~Hz}, 1 \mathrm{H}), 7.02(\mathrm{td}, J=4.1,1.6 \mathrm{~Hz}, 2 \mathrm{H})$; ${ }^{13} \mathrm{C}-\mathrm{NMR}\left(100 \mathrm{MHz}, \mathrm{DMSO}-d_{6}\right) \delta 171.73(\mathrm{~s}), 161.08(\mathrm{~s})$, 147.14 (s), 138.28 (s), 133.36 (s), 130.32 (d, $J=3.8 \mathrm{~Hz})$, $128.34(\mathrm{~d}, J=14.7 \mathrm{~Hz}), 126.65(\mathrm{~d}, J=8.7 \mathrm{~Hz}), 126.08(\mathrm{~s})$, $125.50(\mathrm{~s}), 125.00(\mathrm{~s}), 120.82(\mathrm{~s}), 118.04(\mathrm{~s}), 112.52(\mathrm{~s}) ; \mathrm{R}_{\mathrm{f}}$ $=0.3\left(10 \% \mathrm{MeOH}\right.$ in $\left.\mathrm{CH}_{2} \mathrm{Cl}_{2}\right)$. mp: $177 \sim 181.7^{\circ} \mathrm{C}$ (dec.). MS (ESI) $m / z 265[\mathrm{M}+\mathrm{H}]^{+}$. HRMS $[\mathrm{M}+\mathrm{H}]^{+} \mathrm{C}_{17} \mathrm{H}_{13} \mathrm{O}_{3}$ calcd for 265.2755 found 265.2729.

\section{Cell Culture}

Human embryonic kidney (HEK 293) cells and HepG2 cells, a human hepatoma-derived cell line, were obtained from ATCC (Manassas, VA, USA) and cultured in Dulbecco's modified Eagle's medium (DMEM) supplemented with $10 \%$ fetal bovine serum (FBS), $100 \mathrm{U} / \mathrm{mL}$ penicillin, and $100 \mu \mathrm{g} / \mathrm{mL}$ streptomycin in a humidified atmosphere of $5 \% \mathrm{CO}_{2}$ at $37^{\circ} \mathrm{C}$.

\section{Palmitate Preparation}

Fatty-acid-free bovine serum albumin (BSA) and sodium palmitate were purchased from Sigma-Aldrich Co. (St. Louis, MO, USA). Sodium palmitate was conjugated to fatty-acid-free BSA. Briefly, sodium palmitate was dissolved in sterile phosphate buffered saline by heating and shaking till clear to make a stock solution of $10 \mathrm{mM}$ palmitate. Palmitate stock solution was added to serumfree DMEM containing BSA to prepare a palmitate working solution, which consisted of $1 \mathrm{mM}$ palmitate and 3.4\% 
BSA. This palmitate-conjugated BSA solution was filtersterilized, warmed to $37^{\circ} \mathrm{C}$ before use to ensure palmitate binding to BSA, and diluted to the final concentration $(0.5$ $\mathrm{mM}$ palmitate) in media. Cells in the control group were incubated in the serum-free DMEM containing 1.7\% BSA.

\section{Multiplex Luciferase Assay}

The stable human embryonic kidney (HEK 293) cell line harboring a reporter gene expressed by human grp78 promoter was used as previously described. ${ }^{15}$ Synthesized human grp78 promoter $(-137 \sim+25)$ containing three ER stress response elements (ERSE) in tandem was cloned into pGL4.79 vector (Promega, Madison, USA). A stable human embryonic kidney (HEK 293) cell line harboring the reporter gene was selected under $400 \mu \mathrm{g} / \mathrm{mL}$ of G418 selection pressure. 5000 cells/well were seeded in white 384-well plate (Greiner, Solingen, Germany). After 24 h, Tm or DMSO was added (1 ug/mL final concentration). Following $22 \mathrm{~h}$ incubation, $60 \mu \mathrm{M}$ of EnduRen ${ }^{\mathrm{TM}}$ live cell substrate (Promega, Madison, USA) was added to medium and, after $2 \mathrm{~h}$ incubation, Renilla luciferase (rLuc) activity was measured using EnVision ${ }^{\circledR}$ (Perkin-Elmer). to normalize the rLuc activity, total viable cells were counted using Celltiter-glo ${ }^{\mathrm{TM}}$ reagent (Promega). The 50\% inhibitory concentration $\left(\mathrm{IC}_{50}\right)$ values for tested compounds were determined by non-linear regression analysis of log-dose /response curves using Prism ${ }^{\circledR} 5$ software (GraphPad software Inc., CA, USA). Data from three independent experiments were expressed as the geometric mean $\mathrm{IC}_{50}$ and $95 \%$ confidence intervals $(95 \% \mathrm{CI})$ were calculated.

\section{Cytotoxicity}

Cells were plated in new plates and treated with compounds at different concentration in a parallel manner to the reporter assay. After incubation, cells were treated with Celltiter-glo ${ }^{\mathrm{TM}}$ reagent (Promega), incubated for $30 \mathrm{~min}$. Luminescence was measured using Envision (Perkin Elmer) reader. Cytotoxicity was expressed as the $50 \%$ cytotoxic concentration $\left(\mathrm{CC}_{50}\right)$ values.

\section{Statistical Analysis}

Statistically significant differences were assessed by the Student's $t$-test. A probability value of less than 0.05 was considered significant.

\section{Immunoblot Analysis}

HepG2 cells in a 6-well plate at a density of 500,000 cells/ well were incubated with $500 \mu \mathrm{M}$ of palmitate in the presence or absence of a test compound for $6 \mathrm{~h}$. Fattyacid-free BSA and DMSO were used as vehicle controls. Cells were lysed in RIPA lysis buffer (Cell Signaling Technology, Beverly, MA, USA) supplemented with protease inhibitor cocktail (Calbiochem, San Diego, CA, USA). Proteins in whole cell lysates were resolved by SDS-polyacrylamide gel electrophoresis and transferred onto nitrocellulose membrane (GE Healthcare, Chalfont St. Giles, Buckinghamshire, UK). The membranes were blocked with $5 \%(\mathrm{w} / \mathrm{v})$ skim milk in phosphate-buffered saline containing $0.25 \%(\mathrm{v} / \mathrm{v})$ tween-20 for 1 hour and subsequently incubated with primary antibody overnight at $4{ }^{\circ} \mathrm{C}$ and reacted with horseradish peroxidaseconjugated secondary antibody (Life Technologies, Grand Island, NY). ECL chemiluminescence detection kit (GE Healthcare, Chalfont St. Giles, Buckinghamshire, UK) was used to develop the protein bands. Equal loading of proteins was confirmed by immunoblotting for $\beta$-actin. Antibodies against phospho-PERK and PERK were purchased from Santa Cruz Biotech (Santa Cruz, CA, USA). Anti-phospho-JNK and anti-JNK antibodies were obtained from Cell Signaling Technology (Beverly, MA, USA). Anti- $\beta$-actin antibody was supplied by Sigma-Aldrich Co. (St. Louis, MO, USA).

\section{Results and Discussion Synthesis}

In order to test our hypothesis, we have prepared biphenyl versions of salicylic acid (compounds 16 and 17). Some direct analogues of 3-HNA (1 4, Figure 2) were also examined to compare the structure-activity relationship (SAR). Compound 5 (6-hydroxy-1-naphthoic acid) is a regioisomer of 3-HNA which showed several fold less activity than 3-HNA confirming it is the reasonable starting point of SAR study.

Compound 1 was prepared by replacing a carboxylic acid functional group of 3-HNA with a tetrazole ring. A tetrazole ring is a well-known bioisostere of carboxylic acid due to similar $\mathrm{pKa}$ and flat geometry between them. ${ }^{17}$

As shown Scheme 1, synthesis of 1 started with Fisher esterification on 3-HNA to afford the ethyl ester 6. It was then treated with ammonium hydroxide to afford an amide 7 in 55\% yield which was consecutively converted to a nitrile compound 8 quantitatively under a dehydration condition using $\mathrm{POCl}_{3}$. Reaction of 8 and sodium azide afforded the tetrazole compound 1 in $83 \%$ yield. ${ }^{18}$ 
<smiles>O=C(O)c1cc2ccccc2cc1O</smiles>

3-HNA<smiles>Oc1cc2ccccc2cc1-c1nnn[nH]1</smiles>

1<smiles>[R]c1cc2c([R])c([R])c([R])c([R])c2cc1[R6]</smiles>

$2\left(\mathrm{R}_{1}=\mathrm{R}_{4}=\mathrm{OH}, \mathrm{R}_{2}=\mathrm{CO}_{2} \mathrm{H}, \mathrm{R}_{3}=\mathrm{R}_{6}=\mathrm{R}_{7}=\mathrm{H}\right)$

$3\left(\mathrm{R}_{1}=\mathrm{R}_{4}=\mathrm{R}_{6}=\mathrm{H}, \mathrm{R}_{2}=\mathrm{CO}_{2} \mathrm{H}, \mathrm{R}_{3}=\mathrm{OH}, \mathrm{R}_{7}=\mathrm{Br}\right)$

$4\left(\mathrm{R}_{1}=\mathrm{R}_{3}=\mathrm{R}_{4}=\mathrm{R}_{7}=\mathrm{H}, \mathrm{R}_{2}=\mathrm{CO}_{2} \mathrm{H}, \mathrm{R}_{6}=\mathrm{OMe}\right)$

$5\left(\mathrm{R}_{1}=\mathrm{CO}_{2} \mathrm{H}, \mathrm{R}_{2}=\mathrm{R}_{3}=\mathrm{R}_{4}=\mathrm{R}_{7}=\mathrm{H}, \mathrm{R}_{6}=\mathrm{OH}\right)$

Figure 2 Structure of 3-HNA analogues tested in this study.<smiles>O=C(O)c1cc2ccccc2cc1O</smiles>

3-HNA<smiles>CCOC(=O)c1cc2ccccc2cc1O</smiles>

6<smiles>N#Cc1cc2ccccc2cc1C(=O)O</smiles><smiles>Oc1cc2ccccc2cc1-c1nnn[nH]1</smiles>

1

Scheme I Reagents and conditions (a) $\mathrm{EtOH}, \mathrm{H}_{2} \mathrm{SO}_{4}$, reflux, I d, $95 \%$ (b) $\mathrm{NH}_{4} \mathrm{OH}$, reflux, I h, $55 \%$ (c) $\mathrm{POCl}$, $\mathrm{DMF}$, r.t., $100 \%$ (d) $\mathrm{NaN}$, Et $\mathrm{N}_{3} \mathrm{~N}-\mathrm{HCl}$, toluene, $95{ }^{\circ} \mathrm{C}$, o/n, $83 \%$.

Synthesis of biaryl analogues (16 and 17) is described in Scheme 2. Some aryl boronic acids $(\mathrm{Ar}=\mathrm{a}$ and $\mathrm{b})$ were esterified with 2,3-dimethylbutane-2,3-diol to afford the corresponding boronic esters 9 when necessary. ${ }^{19}$ 5-Iodosalicylic acid 10 and 4-iodosalicylic acid 11 were independently esterified to form the ethyl esters 12 and 13, respectively. Reaction of 12 and 13 and boronic acid $(\mathrm{Ar}=$ $\mathrm{a}$ and $\mathrm{b})$ or the corresponding boronic ester $9(\mathrm{Ar}=\mathrm{c}$ and d) under Suzuki coupling conditions gave biarylsubstituted ethyl salicylates $14 \mathrm{a} \sim 14 \mathrm{~d}$ and $15 \mathrm{a} \sim 15 \mathrm{~d}$, depending on Ar group. ${ }^{20}$ Hydrolysis of the ethyl esters finally gave the corresponding acids, 16a 16d and $17 \mathrm{a} \sim 17 \mathrm{~d}$.

\section{Biological Activity and Structure-Activity Relationships}

Anti-ER stress activity of the compounds, expressed as $\mathrm{IC}_{50}$, was evaluated using our cell-based reporter assay based on multiplex renilla luciferase activity driven by GRP78 gene. Cytotoxicity was also measured using the luciferase assay as described in Methods section, ${ }^{15,16}$ expressed as $\mathrm{CC}_{50}$ and displayed in Table 1 along with $\mathrm{IC}_{50}$.

As shown in Table 1, compounds 2 (4-HNA), 3 (7-bromo-3-HNA) and 4 (6-methoxy-2-naphthoic acid) showed better activity than the parent compound, 3-HNA. Compound 2 showed the best activity among them, but it showed some level of cytotoxicity. Compound 1, a bioisostere of 3-HNA, disappointingly lost quite a portion of the activity indicating carboxylic acid is the best option.

Most compounds showed comparable to better activities to reduce Tm-induced ER stress signal than the parent compound, 3-HNA. The activity was slightly decreased when a naphthalene group of 3-HNA is replaced with a biphenyl group (16a and 17a vs 3-HNA). However, when the naphthalene group of 3-HNA is replaced with a phenylnaphthalene group (16b and 17b), the activities increased by about twofold. When it comes to a pyridine substituent (16c, $d$ and 17c, d), the activities showed somewhat controversial SAR. When the Ar group is 3-pyridyl, 


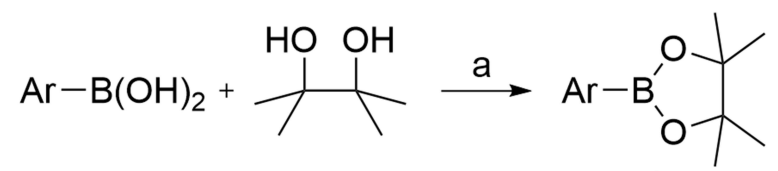

9
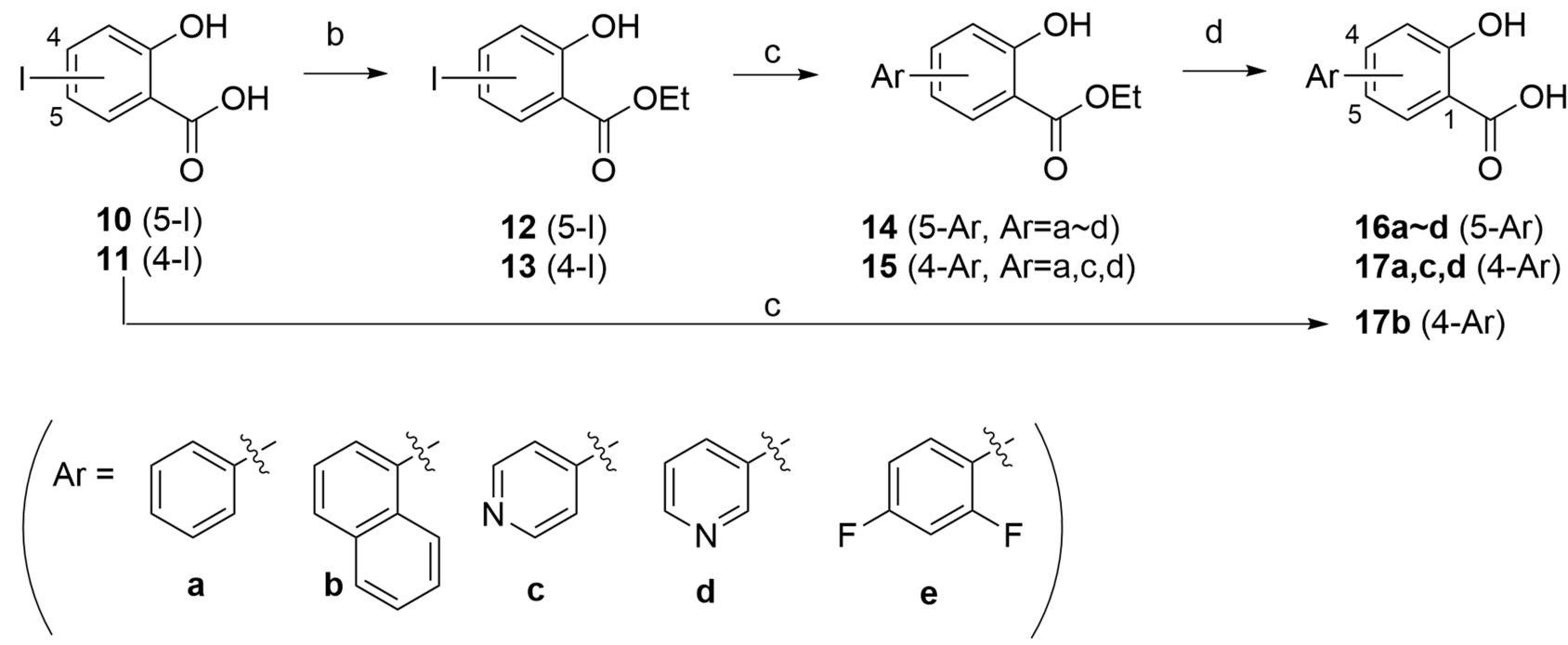

Scheme 2 Synthetic scheme for 5-arysalicylic acid (I6a d) and 4-arylsalicylic acid (I7a d) reagents and conditions (a) $\mathrm{MgSO}_{4}$, dioxane, reflux o/n, (b) $\mathrm{H}_{2} \mathrm{SO}_{4}$, EtOH, reflux for o/n (c) arylboronic acid or $9, \mathrm{Pd}\left(\mathrm{PPh}_{3}\right)_{4}, \mathrm{Na}_{2} \mathrm{CO}_{3}, \mathrm{EtOH} /$ toluene, $85^{\circ} \mathrm{C}$ or dioxane, $90{ }^{\circ} \mathrm{C}, 4 \mathrm{~h}$ (d) $\mathrm{LiOH}, \mathrm{MeOH}, \mathrm{reflux}, 12 \mathrm{~h}$.

$16 \mathrm{~d}$ and $17 \mathrm{~d}$ showed better activity than 3-HNA whether the Ar group is located at the 4-position or 5-position. On the other hand, if the Ar group is 4-pyridyl, 16c containing it at the 5-position totally lost the activity whereas $17 \mathrm{c}$ that

Table I Activity of I 5, 16 and 17 Against Tunicamycin-Induced ER Stress and Cytotoxicity ${ }^{a}$

\begin{tabular}{|l|l|l|l|}
\hline Compounds & EC $_{\mathbf{5 0}}(\mu \mathrm{M})$ & CC $_{\mathbf{5 0}}(\mu \mathrm{M})$ & SI $^{\mathbf{b}}$ \\
\hline $\mathrm{I}$ & $507.3 \pm 57$ & $>2000$ & $>3.9$ \\
2 & $81.6 \pm 16.1$ & $50.4 \pm \mathrm{II}$ & 0.62 \\
3 & $159.8 \pm 27.3$ & $782.5 \pm 72$ & 4.9 \\
4 & $100.7 \pm 6.7$ & $1580 \pm 20 \mathrm{I}$ & 15.7 \\
5 & $1213 \pm 37$ & $3236 \pm 427$ & 2.67 \\
$16 \mathrm{a}$ & $362.0 \pm 55.3$ & $>5000$ & $>13.8$ \\
I6b & $151 \pm 27.5$ & $459 \pm 21$ & 3.06 \\
$16 \mathrm{c}$ & $3419 \pm 216$ & $>5000$ & $>1.46$ \\
$16 \mathrm{~d}$ & $265.7 \pm 77$ & $>5000$ & $>18.9$ \\
I6e & $58.3 \pm 3.5$ & $>5000$ & $>85.7$ \\
I7a & $566.4 \pm 97$ & $>5000$ & $>8.8$ \\
I7b & $196.1 \pm 37$ & $453 \pm 19$ & 2.31 \\
I7c & $325 \pm 59$ & $>5000$ & $>15.4$ \\
I7d & $132 \pm 32$ & $>5000$ & $>37.9$ \\
3-HNA & 328 & 2301 & 7.02 \\
t-UDCA & 5200 & & \\
\hline
\end{tabular}

Notes: ${ }^{a}$ Data represent mean of three experiments in duplicate. ${ }^{b}$ Safety index is expressed as a ratio of $\mathrm{CC}_{50} / \mathrm{EC}_{50}$. has the same Ar group at the 4-position showed almost the same activity than 3-HNA. It seems that there is no general SAR regarding the position of Ar group throughout the analogues. When $\mathrm{Ar}=$ phenyl and 1-naphthyl, 16 (a and $b$ ) showed better activity than 17 ( $a$ and $b$ ), respectively, whereas if Ar = 4-pyridyl and 3-pyridyl, 16 (c and d) showed less activity than 17 (c and d).

Increased activities of $16 \mathrm{~b}$ and $17 \mathrm{~b}$ might be attributed to some level of conformational issues between an $\mathrm{Ar}$ (=naphthalene) group and salicylate group. A molecular dynamics calculation indicated about dihedral angel $\theta \cong$ 20 suggesting different steric factors caused by Ar group than flat naphthalene moiety of 3-HNA. The activity of $16 \mathrm{~b}$, however, is hard to be rationalized in this regard, because it still has the flat conformation like 3-HNA barely generating significant dihedral angel between the Ar group and salicylate group.

As shown in Table 1, 16b and 17b with Ar being naphthalene, showed quite a toxicity to result in undesirable safety window (SI < 3). It indicates that bulky Ar group to generate some level of dihedral angel is not required to be the best analogues. On the other hand, $17 \mathrm{~d}$ that has a flat conformation displayed the best activity and considerable toxicity profile to afford $\mathrm{SI} \cong 40$. It clearly 
confirmed the crucial role of flat aromatic space in the activity. of the compounds shown in Figure 1, compound 1, a bioisostere of 3-HNA, and 5 showed less activity than 3-HNA while compounds 2, 3 and 4 showed better activity. However, 2 and 3 showed low level of safety index whereas 4 showed significant activity with acceptable SI.

With the effect of flat aromaticity on the activity, we also tested 16e which as Ar = 2',4'-difluorophenyl group. 16e has a name Diflusinal and is a non-steroidal anti-inflammatory drug (NSAID) and used as an analgesic and antiinflammatory drug. ${ }^{21}$ Beside anti-ER stress activity, it was reported that $16 \mathrm{e}$ and its derivatives showed considerable level of anti-amyloidosis effect ${ }^{22}$ suggesting the bi-aryl salicylate scaffold potentially have some intrinsic activity against misfolded protein-related pathologies. Structurally, it also has little dihedral angle to form a flat conformation and surprisingly showed the best anti-ER stress activity
$\left(\mathrm{EC}_{50}=58 \mu \mathrm{M}\right)$ and significant toxicity to result in remarkably high level of safety window ( $\mathrm{SI} \cong 90)$.

It is not clearly understood if NSAIDs generally induce or inhibit ER stress although inflammation and ER stress cross talk in many pathological conditions. ${ }^{23}$ As mentioned above, salicylic acid was reported to be a chemical chaperone to ameliorate ER stress. ${ }^{24,25}$ However, there is a report that diclofenac, an NSAID, induced ER stress, demonstrated by up-regulation of BiP (binding immunoglobulin protein, a. k.a., GRP78). ${ }^{26}$ In this study, we report Diflusinal, an NSAID, clearly down-regulated GRP78-driven ER stress signal and related markers (Table 1 and Figure 3).

Next, we investigated the effects of the best compound (16e) on ER stress markers. Compound 16e was treated at various concentrations along with palmitate to HepG2 cells and the changes of some UPR markers were analyzed by Western blot (Figure 3). When sensing ER stress,
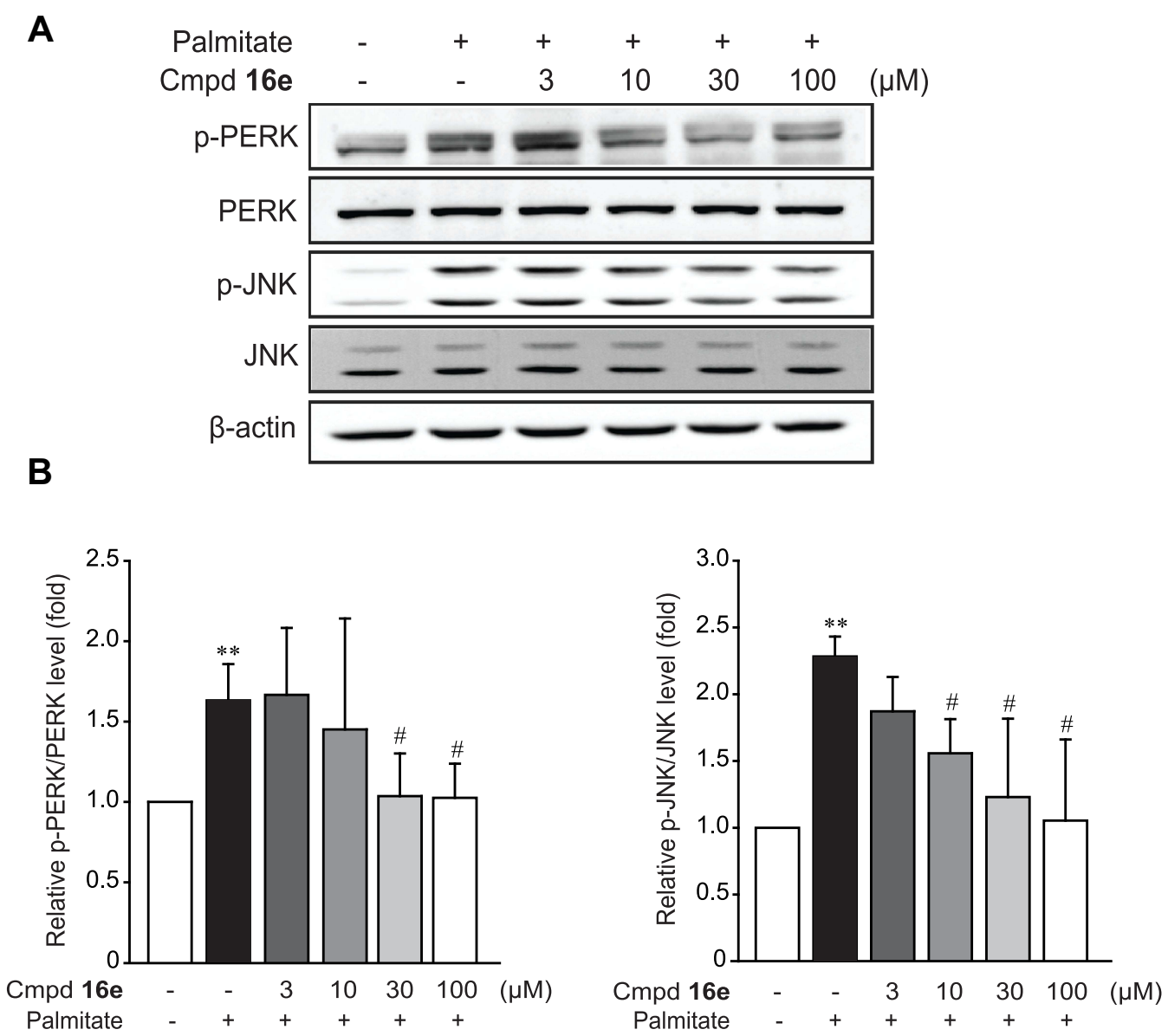

Figure 3 Western blot (A) and densitometry (B) of ER stress markers upon treatment of I6e. Immunoblotting was performed in HepG2 cells incubated with palmitate (500 $\mu \mathrm{M})$ in the presence of increasing concentrations of compound $16 \mathrm{e}$ for $6 \mathrm{~h}$. Bands were quantified by densitometric scanning. The expression levels of phosphorylated PERK and JNK were normalized to those of each total form. Data represent the mean \pm S.D. of three separate experiments. ${ }^{* * P<0.0 I}$ (compared with the BSA control); ${ }^{*} P<0.05$ (compared with the group treated with palmitate alone). 
GRP78 which normally binds to PERK is released from the complex, which is followed by the oligomerization and transphosphorylation of PERK. Compound 16e successfully diminished the phosphorylated PERK induced by palmitate treatment. Level of phosphorylated c-Jun $\mathrm{N}$-terminal kinase (JNK) was also attenuated in line with p-PERK and is usually implicated in apoptosis. The degree of those changes was in concert with the results of our reporter assay, which in turn demonstrated the robustness of our reporter assay.

Although we have shown here that representative ER stress markers are modulated upon treatment of 16e, mechanism of action (MOA) by which the compound decrease ER stress or misfolding load still requires good amount of investigations. Chemical chaperones can be categorized into several groups. ${ }^{12,27}$ The most common type is osmolytes consisting of polar or charged compounds, such as glycerol, trimethylamine N-oxide (TMAO) and proline. They limit free movement of proteins by elevating the density of the solvent, thus preventing aggregation of unfolded proteins. The second group is hydrophobic or detergent-like compounds, eg, sodium salt of PBA, lipids, and detergents. Hydrophobic moiety of them binds to the hydrophobic surface of unfolded proteins to protect them from aggregation. Another category can be pharmacological chaperones such as enzyme inhibitors and receptor ligands. They possibly bind to a target protein to promote proper folding or to transport the misfolded protein. They are supposed to bind the native conformation of the target protein, stabilizing its conformation to push the balance toward the native state. In this regard, our compounds should bind to a target protein in a specific manner toward which our future investigation of MOA and novel compounds will be directed.

In conclusion, we have designed and synthesized arylsubstituted salicylic acid analogues which feature altered aromatic arrangement than the parent compound, 3-HNA. Analogues with naphthalene Ar group showed increased activity but their cytotoxicity also became worse to demonstrate the crucial role of flat aromatic steric effect. The best compound, 16e (Diflusinal), showed almost 6 90 -fold better activity than positive controls. Moreover, it reduced representative ER stress markers such as p-PERK and $\mathrm{p}-\mathrm{JNK}$ in Western blot under more physiologically relevant palmitate-induced ER stress condition. It is suggested that this scaffold could be a platform for further investigation to identify novel chemical chaperones.

\section{Supplementary Materials}

${ }^{1} \mathrm{H}$ - and ${ }^{13} \mathrm{C}-\mathrm{NMR}$ spectrum of unknown compounds are available in Supplementary Information.

\section{Acknowledgments}

This work was supported by the research fund of Hanyang University (HY-2014-N).

\section{Disclosure}

The authors declare no conflicts of interest in this work.

\section{References}

1. Walter P, Ron D. The unfolded protein response: from stress pathway to homeostatic regulation. Science. 2011;334(6059):1081-1086. doi:10.1126/science. 1209038

2. Xu C, Bailly-Maitre B, Reed JC. Endoplasmic reticulum stress: cell life and death decisions. J Clin Invest. 2005;115(10):2656-2664. doi: $10.1172 /$ jci126373

3. Hetz C, Chevet E, Harding HP. Targeting the unfolded protein response in disease. Nat Rev Drug Discov. 2013;12(9):703-719. doi:10.1038/nrd3976

4. Lee WS, Yoo WH, Chae HJ. ER stress and autophagy. Curr Mol Med. 2015;15(8):735-745. doi:10.2174/1566524015666150921105453

5. Iannitti T, Palmieri B. Clinical and experimental applications of sodium phenylbutyrate. Drugs $R \quad D$. 2011;11(3):227-249. doi:10.2165/11591280-000000000-00000

6. Boyce M, Bryant KF, Jousse C, et al. A selective inhibitor of eIF2a dephosphorylation protects cells from ER stress. Science. 2005;307 (5711):935-939. doi:10.1126/science. 1101902

7. Ozcan U, Yilmaz E, Ozcan L, et al. Chemical chaperones reduce ER stress and restore glucose homeostasis in a mouse model of type 2 diabetes. Science. 2006;313(5790):1137-1140. doi:10.1126/science.1128294

8. Kong FJ, Wu JH, Sun SY, Zhou JQ. The endoplasmic reticulum stress/autophagy pathways is involved in cholesterol-induced pancreatic beta-cell injury. Sci Rep. 2017;7(1):44746. doi:10.1038/ srep44746

9. Park S, Aintablian A, Coupe B, Bouret SG. The endoplasmic reticulum stress-autophagy pathway controls hypothalamic development and energy balance regulation in leptin-deficient neonates. Nat Commun. 2020;11(1):1914. doi:10.1038/s41467-020-15624-y

10. Uppala JK, Gani AR, Ramaiah KVA. Chemical Chaperone, TUDCA unlike PBA, mitigates protein aggregation efficiently and resists ER and non-ER stress induced HepG2 cell death. Sci Rep. 2017;7 (1):3831. doi:10.1038/s41598-017-03940-1

11. Goddard-Borger ED, Tropak MB, Yonekawa S, et al. Rapid assembly of a library of lipophilic immunosugars via the thiol-ene reaction yields promising pharmacological chaperones for the treatment of Gaucher disease. J Med Chem. 2012;55(6):2737-2745. doi:10.1021/ jm201633y

12. Pereira DM, Valentao P, Andrade PB. Tuning protein folding in lysosomal storage diseases: the chemistry behind pharmacological chaperones. Chem Sci. 2018;9(7):1740-1752. doi:10.1039/ c7sc04712f

13. Tufanli S, Akillilar PT, Acosta-Alvear D, et al. Targeting IRE1 with small molecules counteracts progression of atherosclerosis. Proc Natl Acad Sci USA. 2017;114(8):e1395-e1404. doi:10.1073/ pnas. 1621188114

14. Jeong KW, Ku JM, Park MW, et al. Hydroxynaphthoic acids identified in a high throughput screening potently ameliorate endoplasmic reticulum stress as novel chemical chaperones. Chem Pharm Bull. 2013;61(7):740-746. doi:10.1248/cpb.c13-00251 
15. Choi H, Yun W, Lee JH, et al. Synthesis and anti-endoplasmic reticulum stress activity of $\mathrm{N}$-substituted-2-arylcarbonylhydrazinecabothioamides. Med Chem Res. 2019;28(12):2142-2152. doi:10.1007/ s00044-019-02442-1

16. Park SM, Choi J, Nam TG, et al. Anti-diabetic effect of 3-hydroxy2-naphthoic acid, an endoplasmic reticulum stress-reducing chemical chaperone. Eur J Pharmacol. 2016;779:157-167. doi:10.1016/j. ejphar.2016.03.023

17. Tagad HD, Hamada Y, Nguyen JT, et al. Design of pentapeptidic BACE1 inhibitors with carboxylic acid bioisosteres at P1' and P4 positions. Bioorg Med Chem. 2010;18(9):3175-3186. doi:10.1016/j. bmc.2010.03.032

18. Goguro K, Oga T, Mitsui S, Orita R. Novel synthesis of 5-substituted tetrazoles from nitriles. Synthesis. 1998;6:910-914. doi:10.1055/ s-1998-2081

19. Song T, Rao X, Cui Y, Yang Y, Qian G. Synthesis and luminescent properties of color-tunable lanthanide complexes with 5-(pyridin4-yl)isophthalic acid. $J$ Alloys Compd. 2013;555:22-27. doi:10.1016/j.jallcom.2012.12.030

20. Mendieta MAEP, Negri M, Jagusch C, et al. Synthesis, biological evaluation, and molecular modeling of abiraterone analogues: novel CYP17 inhibitors for the treatment of prostate cancer. $J$ Med Chem. 2008;51(16):5009-5018. doi:10.1021/jm800355c

21. Maria V, Joan N, Parra L, et al. Tuning transthyretin amyloidosis inhibition properties of iododiflusinal by combinatorial engineering of the nonsalicylic ring substitutions. ACS Comb. Sci. 2015;17 (1):32-38. doi:10.1021/co5001234
22. Adamski-Werner SL, Palaninathan SK, Sacchettini JC, et al. Diflusinal analogues stablize the native state of transthyretin. Potent inhibition of amyloidogenesis. J Med Chem. 2004;47(2):355-374. doi:10.1021/jm030347n

23. Dandekar A, Mendez R, Zhang K. Cross talk between ER stress, oxidative stress, and inflammation in health and disease. Methods Mol Biol. 2015;1295:205-214. doi:10.1007/978-1-4939-2522-3_15

24. Alhusaini S, McGee K, Schisano B, et al. Lipopolysaccharide, high glucose and saturated fatty acids induce endoplasmic reticulum stress in cultured primary human adipocytes: salicylate alleviates this stress. Biochem Biophys Res Commun. 2010;397(3):472-478. doi:10.1016/j. bbrc.2010.05.138

25. Silva AM, Wang D, Komar A, et al. Salicylates trigger protein synthesis inhibition in a protein kinase R-like endoplasmic reticulum kinase-dependent manner. J Biol Chem. 2017;282(14):10164-10171. doi:10.1074/jbc.M609996200

26. Niu X, Graaf IAM, Bij HA, Groothuis GMM. Precision cut intestinal slices are an appropriate ex vivo model to study NSAID-induced intestinal toxicity in rats. Toxicol in Vitro. 2014;28(7):1296-1305. doi:10.1016/j.tiv.2014.06.010

27. Papp E, Csermely P. Chemical chaperones: mechanisms of action and potential use. In: Starke K, Gaestel M, editors. Molecular Chaperones in Health and Disease. Handbook of Experimental Pharmacology. Vol. 172. Heidelberg: Springer; 2006: 405-416. doi:10.1007/3-540-29717-0_16.

\section{Publish your work in this journal}

Drug Design, Development and Therapy is an international, peerreviewed open-access journal that spans the spectrum of drug design and development through to clinical applications. Clinical outcomes, patient safety, and programs for the development and effective, safe, and sustained use of medicines are a feature of the journal, which has also been accepted for indexing on PubMed Central. The manuscript management system is completely online and includes a very quick and fair peer-review system, which is all easy to use. Visit http://www. dovepress.com/testimonials.php to read real quotes from published authors. 